\title{
SEJARAH PERKEMBANGAN KETHOPRAK SISWO BUDOYO
}

\author{
Endang Waryanti \\ FKIP Universitas PGRI Nusantara Kediri
}

\begin{abstract}
This article describe about history of traditional theatre art. This call Kethoprak Siswo Budoyo. The theatre group of Kethoprak Siswo Budoyo lead by Ki Siswondo who has high acting talent. He is very popular in Javanesse community that like show theatre. Kethoprak Siswo Budoyo always give morality, spirituality and sociaty value to audience. Therefore kethoprak Siswo Budoyo have some fanatic fans. Everyone like Kethoprak Siswo Budoyo because this theatre group teach character education.
\end{abstract}

Key word : history, kethoprak, character education

\section{PENDAHULUAN}

Kethoprak merupakan seni sandiwara tradisional Jawa. Sebelum menguraikan sejarah perkembangan kethoprak Siswo Budoyo terlebih dahulu diuraikan mengenai asal-usul kethoprak. Uraian sejarah asal-usul diambil atau bersumber pada buku hasil Penelitian Proyek Pembinaan Kesenian Direktorat Pembinaan Kesenian Dirjen Kebudayaan Departemen Pendidikan dan Kebudayaan Republik Indonesia, kedua buku hasil Proyek Penelitian dan Pengkajian Kebudayaan Nusantara (Javanologi) Direktorat Jendral Kebudayaan Departemen Pendidikan dan Kebudayaan.

Penelitian tersebut menyimpulkan, kethoprak lahir di Surakarta sekitar tahun 1908, diciptakan oleh almarhum Raden Mas Tumenggung Wreksodiningrat; walaupun sebenarnya sebelum kethoprak memperoleh wujud seperti itu dapat dimengerti bahwa prototipe kethoprak semula berasal dari alunan irama gejog yang lazim dilakukan oleh petani dengan mempergunakan lesung. Suara berirama ini akhirnya diikuti oleh tari-tarian. Perbedaan antara pemain dan penonton masih sulit dibedakan karena keterikatan pemain dan penonton sangat erat dan kesempatan berpartisipasi terbuka lebar.

Selanjutnya tradisi ini masuk ke golongan priyayi dan ditangani oleh golongan priyayi. Beliaulah yang membina kethoprak pada waktu itu. Kethoprak pada masa itu menggunakan alat-alat pukul sebuah lesung, kendang, terbang dan seruling. Pemain utamanya Ki Wisangkara dan mbok Gendra atau lebih dikenal Nyi Badur. Lagu-lagu yang sering mengiringi antara lain Kuputarung, Megamendung, Simak-simak, Buluktiba, Randangangsu (Bratawijaya, 1977 : 1321).

Cerita yang dibawakan menceritakan seorang petani sedang mencangkul di sawah. Istrinya menyusul dengan membawa makanan kiriman. Alat yang dibawanya berupa tenggok dan cangkul. Penampilannya dengan cara menari-nari. Kostum atau pakaiannya masih sederhana sekali. Mengingat penampilannya lucu, maka penonton sering menyebutkan dengan tontonan badutan. Dialognya 
sebagian dalam bentuk nyanyian atau tembang, sebagian lagi berbentuk gancaran atau dialog dengan bahasa sehari-hari (Soedarsono, $1999: 61$ ).

\section{Sejarah Asal-usul Kethoprak Siswo Budoyo}

Kesuburan kethoprak tidak saja didominasi oleh masyarakat Surakarta, Yogyakarta dan sekitarnya, tetapi masyarakat Jawa Timur tidak kalah pentingnya dalam ikut melestarikan dan membudayakan (menghidupkan) seni budaya tradisional yang disebut kethoprak. Hal ini terbukti dengan adanya perkumpulan kethoprak seperti : Wahyu Budoyo dari Kediri yang dipimpin oleh ibu Suci, kethoprak Siswo Budoyo dipimpin oleh Siswondho Hs dari Kalangbret Tulung Agung. Yang terakhir ini merupakan kethoprak gaya baru yang cukup dikenal oleh masyarakat khususnya suku Jawa.

Perbedaan kethoprak gaya lama dan gaya baru yang menyolok adalah segi pementasan. Dialog-dialog banyak mempergunakan nyanyian. Peralatan yang digunakan untuk mengiringinya sangat sederhana. Berbeda dengan kethoprak gaya baru, pementasan cerita tidak lagi banyak diwarnai dengan dialog yang berupa nyanyian. Nyanyian dipergunakan untuk waktu tertentu saja, sedangkan pembicaraan tokohnya sudah berupa dialog. Begitu juga peralatan yang mengiringinya sudah lengkap dan cukup modern.

Untuk mengetahui sejarah perkembangan kethoprak di Jawa Timur khususnya kethoprak Siswo Budoyo, terlebih dahulu ditampilkan secara garis besar asal-usul kethoprak yang berasal dari kota Tulung Agung ini. Tokoh utama kethoprak di daerah ini diawali oleh Raden (Bupati) Tulung Agung yang sering disebut dengan Kanjeng Wajak (1890-1923).

Berdasarkan ceramah Ki Siswondho Hs di kantor Lembaga Penelitian Kebudayaan Yogyakarta di Bulaksumur, bahwa kethoprak sebelum memperoleh bentuk seperti sekarang ini diawali oleh adanya keciprak (Sastroamijoyo, 1982 : 8). Instrumen atau gamelannya telah dilengkapi dengan bonang renteng, angklung, kenong, gender dan gending jedor. Adapun lakon yang tampil untuk menyambut tamu adalah babad, misalnya Babad Tulung Agung. Setelah itu, lakon masih berkisar pada masalah pedesaan, seperti : Paman Tani Utun, Sri Sadono. Begitu sejarah asal-usul kethoprak di Tulung Agung tempo dulu.

Paguyuban kesenian kethoprak gaya baru Siswo Budoyo lahir dari kawasan kota Tulung Agung tepatnya pada tanggal 19 Juni 1958 di desa Kiping, Kecamatan Gondang Kawedanan Kalangbret. Ki Siswondho Hs bersama Bapak Ruslan dan Bapak Mulyadi mendirikan suatu paguyuban kethoprak dengan nama Siswo Budoyo.

Berdasarkan hasil wawancara dengan $\mathrm{Ki}$ Siswondho $\mathrm{Hs}$ pimpinan kethoprak Siswo Budoyo diperoleh keterangan, bahwa pemberian nama itu didasarkan atas dua kata yakni siswo dan budoyo yang berarti murid atau cantrik yang mengabdi pada budaya (kesenian) khususnya kesenian Jawa. Dengan nama itu dimaksudkan agar paguyuban kethoprak Siswo Budoyo dapat: menggali, menggubah, memelihara, dan melestarikan martabat seni budaya bangsa khususnya seni tradisional. Dengan perantaraan paguyuban kethoprak ini dapat memberikan hiburan pada masyarakat juga memberikan tuntunan dan pendidikan pada masyarakat untuk cinta terhadap budaya bangsa sendiri. Lebih jauh bertujuan 
menanggulangi ekspansi kebudayaan asing yang tidak sesuai dengan kepribadian bangsa Indonesia.

Selama tahun 1958-1962 Siswo Budoyo hanya bermain di kota Tulung Agung dan sekitarnya, tetapi sejak tahun 1963 sampai sekarang Siswo Budoyo telah menjadi sebuah kethoprak keliling dan berpindah-pindah tempat. Hampir seluruh pelosok kota di Jawa Timur pernah menjadi tempat pentas kethoprak Siswo Budoyo.

Berdasarkan informasi yang diperoleh dari angket dan hasil wawancara dapat diketahui bahwa semula Siswo Budoyo didukung oleh sekitar 35 orang seniman dan seniwati; namun setelah tahun tujuh puluhan yakni tahun 1979 telah bertambah menjadi 120 orang. Tahun 1982 meningkat lagi menjadi 140 orang seniman dan seniwati.

\section{HASILPENELITIAN DAN PEMBAHASAN \\ Perkembangan Kethoprak Siswo Budoyo}

Jika dilihat kondisi objektif, baik prasarana dan sarana yang dimiliki kethoprak gaya baru Siswo Budoyo tergolong dalam kelompok kethoprak besar. Maksudnya berdasarkan jumlah anggota, ukuran gedung, ukuran panggung, jumlah dekor, lampu, peralatan dan kursi penonton, jaminan sosial serta kekayaan (material) organisasi Siswo Budoyo memungkinkan diklasifikasikan jajaran besar. Kriteria ini didasarkan pendapat Soedarsono (1999 : 72) menyimpulkan bahwa:

"Kethoprak keliling besar anggotanya berkisar 125 sampai 200 orang, ukuran gedung sekitar 80 × 30 meter. Panggung 20 × 18 meter. Jumlah dekor layar 20 buah dengan ukuran 12 ban (10 x 4,5 meter), lampu 80 buah, jumlah peralatan kira-kira 15, jumlah kursi kurang lebih 1500 . Honorarium tiap anggota minimal Rp. 750 tiap malam, perawatan kesehatan (periksa dokter dan obat) menjadi tanggungan organisasi atau manager; begitu juga biaya bersalin anggota, biaya kematian (meninggal dunia) dan perjalanan pulang pergi menengok keluarga atau cuti."

Ukuran atau kriteria itu bagi kethoprak gaya baru Siswo Budoyo sebagian besar telah terpenuhi, sehingga dengan demikian Siswo Budoyo tergolong pada kethoprak besar. Begitu pula apabila diikuti sejarah perkembangan sejak berdirinya, yakni tahun 1958 sampai saat ini Siswo Budoyo mengalami perkembangan dan pertumbuhan yang pesat. Perkembangan itu tidak saja terjadi dalam bentuk kuantitas pendukung Siswo Budoyo, namun dalam kualitas pun tampak jelas perkembangannya.

Berbagai faktor pendukung perkembangan Siswo Budoyo dapat disebutkan antara lain : sistem organisasi (kebersamaan) dan faktor teknik penyajian. Sistem organisasi yang berlaku dan dipakai oleh pemimpin Siswo Budoyo lebih bersifat kooperatif. Artinya perkumpulan itu milik bersama (semua anggota), kekuasaan di tangan pengurus (manager) yang telah dipilih (Soedarsono, 1999 : 73). Kekayaan dari keuntungan pementasan milik bersama, semua anggota mempunyai tanggung jawab atas kerugian yang diterima atau dideritanya. Faktor teknik misalnya penyajiannya selalu didasarkan pada pengarahansutradara dan berdasarkan teks. Namun demikian bukan berarti para 
pemain bersifat pasif,tetapi karena pendukungSiswo Budoyo merupakan orangorang yangkreat if danberbakat, oleh karena itu dalam penampilannya dapat memukay para penonton. Satu hal lagikeistimewaan Siswo Budoyo dengan dilengkapi peralatan-peralatana yang cukup modern maka hal ini memungkinkan berpengaruh positif terhadap kelangsungan dan perkembangan kethoprak itu sendiri, sesuai dengan tuntutan jaman dan selera masyarakat pendukungnya.

Faktor lain yang merupakan pendukung keberhasilan Siswo Budoyo, yakni sarana dan prasarananya cukup modern. Kondisi seperti ini besar peranannya dalam perkembangan kethoprak gaya baru. Namun faktor-faktor itu tidak berarti jika pengolahannya tidak terarah dan terencana dengan cara yang baik. Untuk lebih mendewasakan dan menyempurnakan kethoprak Siswo Budoyo maka dibentuklah suatu yayasan Siswo Budoyo, tepatnya tanggal 1 Desember 1981. Pembentukan dengan berbagai pengurus memungkinkan perencanaan dan perkembangan Siswo Budoyo cepat terwujud. Fungsi yayasan tidak saja untuk menyiapkan kader-kader Siswo Budoyo, tetapi lewat jalur ini kelestarian hidup dan perkembangannya dapat terkontrol dan terarah, lebih jauh kesejahteraan pendukungnya dapat terjamin dengan baik.

Berbagai unsur dan bidang kemajuan perkembangan yang dialami kethoprak gaya baru Siswo Budoyo dapat diperinci sebagai berikut :

\section{Unsur Cerita}

Jika diikuti sejarah perkembangan kethoprak yang mula-mula jadi bahan cerita atau lakon antara lain : cerita klasik, legenda dan cerita khayal seperti Panji dan Joko Tarub, kemudian meningkat ke cerita-cerita Menak, Mesiran dan Cina (Gazali, 1958: 48).

Perkembangan semacam ini juga dialami dan dilakukan oleh kethoprak Siswo Budoyo. Perkembangan itu pada dasarnya selaras dengan perkembangan jaman dan perkembangan penonton. Mengingat Siswo Budoyo telah menyatu dengan masyarakat, maka kethoprak ini dituntut untuk memenuhi dan mengikuti selera penonton kethoprak sebagai satu bentuk kesenian yang dikenal untuk masa. Karenanya dalam penataan dan penggarapan diprioritaskan pada selera masyarakat (Soedarsono, 1999 : 77). Unsur estetika, etika, pendidikan dan kontrol sosial tidak ditinggalkan, walaupun masyarakat menuntut sesuatu Siswo Budoyo mempunyai kewajiban dan sekaligus hak tetap untuk mempertahankan ciri khasnya.

\section{Unsur Peralatan Panggung}

Peralatan panggung dalam hal ini meliputi : pengeras suara, dekorasi, lampu termasuk juga peralatan musik gamelan. Peralatan-peralatan yang dimiliki Siswo Budoyo semakin hari semakin bertambah banyak, lengkap dan modern. Dapat diberikan contoh pemakaian slide sebagai alat pengubah suasana (hujan, awan atau api). Kemajuan-kemajuan teknologi yang ada dimanfaatkan oleh Siswo Budoyo sehingga dengan demikian akan semakin tampak maju. Adanya spot light dan berbagai peralatan modern yang dimiliki dan digunakan untuk kelengkapan pementasan. Hal semacam ini pada dasarnya dimaksudkan untuk lebih menghidupkan pementasan dan terlebih lagi untuk mendukung perkembangan Siswo Budoyo sendiri. 


\section{Unsur Teknik dan Akting}

Baik teknik dan penampilan akting bagi kethoprak Siswo Budoyo semakin tampak lebih mantap atau meyakinkan penggemar kesenian tradisional ini. Berbagai teknik misalnya : tata lampu, teknik drama, teknik dialog dan berbagai jenis tari dan teknik perang dengan bermacam-macam seni bela diri telah diajarkan dan dikuasai oleh para pemain Siswo Budoyo.

Manager Siswo Budoyo sengaja mendatangkan berbagai ahli yang berkaitan dengan pementasan kethoprak dimaksudkan untuk menambah pengetahuan, mendidik pemain-pemain kethoprak Siswo Budoyo agar semakin trampil dan berpengalaman. Demikian dengan kegiatan dan penambahan waktu latihan dimaksudkan untuk lebih memantapkan penampilan-penampilan berikutnya.

Kegiatan ini bertujuan agar Siswo Budoyo semakin tambah maju, dan ketrampilan demi ketrampilan terus diupayakan untuk meningkatkan jumlah penonton kesenian tradisional yang disebut kethoprak. Kemajuan di bidang teknik dan akting bagi warga Siswo Budoyo merupakan suatu hal yang mendapat perhatian khusus.

\section{Unsur Penonton}

Selain unsur sarana dan prasarana berpengaruh terhadap perkembangan perkumpulan Siswo Budoyo, maka faktor penonton pun tidak kalah pentingnya dengan unsur-unsur di atas. Dengan penonton yang cukup banyak, misalnya pemasukan yang diperoleh semakin meningkat. Hal ini akan berpengaruh terhadap kelestarian hidup dan perkembangan kethoprak itu sendiri. Karena tanpa adanya pemasukan yang cukup mustahil kelangsungan hidup kethoprak itu bertahan lama. Pernyataan Soedarsono (1999 : 80), "hambatan-hambatan kethoprak keliling yang menjadi suram prospeknya itu terutama karena daya beli penonton kethoprak masih rendah. Sehingga harga produksi juga rendah, padahal biaya produksi selalu meningkat."

Siswo Budoyo bagi masyarakat Jawa khususnya masyarakat Jawa Timur merupakan kethoprak yang cukup dikenal dan dianggap cukup modern. Kenyataan ini mengingatkan bahwa penggemar kethoprak Siswo Budoyo cukup banyak dan merakyat. Masyarakat pencintanya pun menyatakan bahwa Siswo Budoyo bagi mereka tidaklah mahal, walaupun bila kita ingat pementasan Siswo Budoyo tidak kecil biayanya.

Kelangsungan tampil dan hadir Siswo Budoyo bukan karena dana yang diperoleh melalui pentas keliling, tetapi kethoprak satu ini telah melangkah lebih maju, yakni terjun ke bidang studio rekaman, baik itu lewat kaset maupun video kaset. Lewat acara televisi sebulan sekali merupakan tambahan pemasukan yang tidak kecil bagi Siswo Budoyo.

\section{Unsur Perencana dan Manajemen}

Kehidupan dengan variasi jatuh bangun dan kekaburan arah maupun sifat dari kebanyakan perkumpulan kethoprak karena adanya pemikiran dan penggarapan yang serius masalah pengelolaan (Bratawijaya, 1977 : 52). Masalah pengelolaan merupakan faktor penentu kelestarian organisasi kethoprak. Bidangbidang yang memerlukan pengelolaan antara lain : perencanaan, teknik artistik, 
organisasi, produksi, keuangan dan administrasi. Cara-cara ini merupakan wahana perwujudan pengembangan suatu organisasi, termasuk juga kethoprak Siswo Budoyo.

Kethoprak gaya baru Siswo Budoyo di bawah pimpinan Ki Siswondho Hs telah mengupayakan langkah-langkah di atas. Satu bukti adalah terbentuknya yayasan Siswo Budoyo. Yayasan ini tidak sekedar untuk kepentingan kethoprak, tetapi juga merupakan suatu alat perwujudan kesejahteraan warga Siswo Budoyo. Bentuk yang lebih nyata misalnya dengan didirikannya TK (Taman Kanak-Kanak) Siswo Budoyo.

Pengelolaan dan perencanaan yang cukup mantap membawa Siswo Budoyo ke perkembangan yang lebih modern. Dengan memperhatikan beberapa unsur dan fakta yang dimiliki Siswo Budoyo, maka kethoprak gaya baru ini dapat menduduki posisi yang cukup dominan di antara kethoprak-kethoprak lain yang masih hidup di tengah-tengah masyarakat.

\section{Cerita-cerita yang Telah Dipentaskan Kethoprak Siswo Budoyo}

Cerita yang pernah dipentaskan Siswo Budoyo mengalami perkembangan jumlahnya. Lakon yang pertama dipentaskan sekitar cerita-cerita kejawen dan seterusnya melangkah dengan penampilan-penampilan cerita Panji, Mesiran, dan Cina.

Jika diklasifikasikan secara kuantitatif cerita yang pernah dipentaskan kethoprak Siswo Budoyo berjumlah kurang lebih 160 buah cerita. Untuk lebih konkritnya cerita-cerita itu antara lain : cerita kejawen, Majapahitan, Panji, Mesiran, Cina, kepahlawanan, roman, silat, horor, humor, detektif, cerita rakyat atau dongeng rakyat populer, cerita seri atau cerita bersambung. Berdasarkan hasil wawancara dengan Ki Siswondho Hs diperoleh keterangan bahwa :

\section{Cerita Kejawen}

Cerita kejawen ialah cerita jaman kerajaan Demak dan sebelumnya, yang menggunakan kostum ikat kepala, kain batik, surjan atau beskap. Cerita yang menggunakan kostum tersebut adalah Babad Tanah Jawi, Berdirinya Yogyakarta, Arya Penangsang, Tudung Madiun, Pangeran Kencet, Sinuwun Seda Krapyak (Clifford Geertz, 1981: 92).

\section{Cerita Majapahitan}

Cerita Majapahitan ialah cerita jaman Majapahit dan masa sebelum kerajaan Majapahit, yakni sampai jaman kerajaan Kediri, Singosari, Pajajaran. Kostum yang digunakan adalah gelung, pilis kepala, kain batik bukan batik Solo dan Yogyakarta yang bercorak candi, congokan (gaya Pekalongan) dan tidak memapaki baju atau gaya rompi. Cerita yang menggunakan kostum tersebut adalah Kamandaka, Ken Arok, Jaya Katwang, Putri Duyung, Joko Thole, Ranggalawe Tuban, dan Pemberontakan Ra Kuti.

\section{Cerita Panji}

Cerita Panji ialah cerita jaman Kediri, kostum yang digunakan adalah kostum gedog (mendekati wayang dan menggunakan irah-irahan). Cerita yang menggunakan kostum tersebut adalah : Panji Semirang, Angraeni Larung, Andeande Lumut, Enthet, Candra Kirana Bakul Jamu, Timun Emas, Keong Emas, Bancak Doyok, dan Melati Putih Edan. 


\section{Cerita Mesiran}

Cerita Mesiran ialah cerita yang dalam pementasannya menggunakan kostum Mesiran, yaitu : jobahan, ubel (serban); misalnya : cerita Mesir, Bagdad dan cerita Islam. Cerita yang menggunakan kostum tersebut adalah Putri Johar Manik, Aladin, Ali Baba, Umar Amir, Sirat Pencuri Bagdad, Syamsul Hilal, Tabuh Hari Raya Idul Fitri dan Putri Paresade.

Cerita India, Romawi memakai kostum jobahan, tetapi tidak memakai serban. Cerita yang menggunakan kostum tersebut adalah Putri Sawitri, Lonceng Natal, Romeo Yulia, Kelahiran Yesus, Nabi Musa, Laela Majnun, Kapten Lazaro, dan Putri Damayanti.

\section{Cerita Cina}

Cerita Cina adalah cerita yang menggunakan kostum Cina. Cerita yang menggunakan kostum tersebut adalah : cerita Sampek Engtay, Sie Jiem Koei dan Putri Merak (Muangtai).

\section{Cerita Kepahlawanan}

Cerita kepahlawanan ialah cerita yang mengandung tema atau dititikberatkan pada tema kepahlawanan, dan yang termasuk cerita ini adalah Pangeran Diponegoro, Nyai Ageng Serang, Gajah Mada, Retno Dumilah, Probo Retno, Trunojoyo, Erlangga Narotama, Untung Surapati, Joko Tingkir Suwita, Sri Wulandari, Patih Jelantik, Sungging Purbangkara, Syeh Jangkung dan Shampo Khong.

Cerita fiksi atau carangan juga termasuk non fiksi mengandung unsur kepahlawanan, antara lain Naga Sasra Salangit di Langit Singosari, Pahlawan Sudra, Mahabharata dan I Swasta Setahun di Bedahulu. Badai Laut Selatan, Api di Bukit Menoreh, Manggala Yuda Sudira Prana.

\section{Cerita Roman}

Cerita roman ialah cerita yang mengandung tema atau dititikberatkan pada cerita yang bertema cinta (romantis). Cerita jenis ini adalah Roro Mendut, Raga Padmi, Jaya Prana Layonsari, Kamandoko, Sri Huning, Putri Duyung, Rencong Aceh, Joko Tarub, Labuh Tresno Saboyo Pati dan Putri Sedah Merah.

\section{PENUTUP}

Pementasan pertama dilakukan pada tahun 1909 dalam rangka perkawinan agung Sri Paku Alam VII, bertempat di Kepatihan Surakarta dengan putri Sri Susuhunan Paku Buwana X yang bernama GBRA Retno Puwasa.Perkembangan selanjutnya ditandai dengan lahirnya kethoprak Krido Madya Utomo (1924). Kethoprak ini masuk wilayah Yogyakarta sekitar tahun 1925 dengan penampilan pertama di Demangan. Pementasan ini membawa pengaruh positif terhadap kethoprak di daerah Yogyakarta. Perkumpulan kethoprak selanjutnya tidak sekedar diiringi dengan lesung, tetapi masyarakat Yogyakarta menambah dengan peralatan gamelan.

Gaya dialog dagelan atau lawak untuk peran abdi, sedang dialog tembang digunakan pada adegan-adegan sedih atau percintaan, serta waktu pasewakan agung kerajaan. Unsur pakaian mengalami perkembangan pada jumlah cerita yang ditampilkan semakin bertambah banyak. Ini merupakan ciri kethoprak peralihan. 
Berdirinya kethoprak Langen Wanodya (1928) di Yogyakarta merupakan babakan kethoprak gamelan. Kethoprak ini sudah menuju pada bentuk kethoprak profesional yang pernah berkeliling ke Bandung, Jakarta bahkan pernah tampil di kawasan timur seperti Semarang dan Surabaya. Pertumbuhan dan perkembangan bentuk kethoprak pada masa ini sudah mulai tampak jelas.

Dengan demikian hadirnya kethoprak pada masa itu menggugah munculnya perkumpulan-perkumpulan kethoprak lainnya. Dapat dikatakan tumbuhnya kesenian itu semakin subur. Di antaranya muncul kethoprak Krido Mudo (Yogyakarta, 1929), kethoprak Krido Raharjo (Yogyakarta 1932), kethoprak Wargo Wandowo (Yogyakarta 1937). Jaman penjajahan Jepang dan masa setelah kemerdekaan kehidupan kethoprak semakin maju pesat.Menyimak perkembangan kethoprak sampai sekarang secara ringkas dapat diperinci atas tiga periode : tahun 1887 sampai 1925 periode kethoprak lesung, tahun 1925 sampai tahun 1927 periode kethoprak peralihan dan tahun 1927 sampai sekarang periode kethoprak gamelan.

\section{Daftar Pustaka}

Bratawijaya, 1977. Mengungkap dan Mengenal Budaya Jawa. Jakarta : Pradaya Paramita.

Clifford Geertz, 1981. Abangan, Santri, Priyayi dalam Masyarakat Jawa. Terjemahan Aswab Mahasin. Jakarta: Pustaka Jaya.

Gazali. 1958. Langgam Sastra Lama. Jakarta: Balai Pustaka.

Sastroamijoyo, 1982. Renungan tentang Pertunjukan Wayang Kulit. Jakarta: Kinta.

Soedarsono, 1999, Metodologi Penelitian Seni Pertunjukan, MSPI, Yogyakarta. 